\title{
O HOMEM NOVO E O FEITIÇO DO IMPÉRIO: A POLÍTICA DA LITERATURA COLONIAL PORTUGUESA DO SÉCULO XX
}

\author{
Mario Lugarinho \\ (Universidade de São Paulo)
}

\section{RESUMO}

O conceito de "homem novo" no Estado Novo fomentou boa parte da Literatura Colonial, promovida pelos concursos da Agência Geral das Colônias (1926-1974). A narrativa O feitiço do Império, em sua dupla forma (cinema e romance), não fugiu à regra, entretanto, propôs formas diversas de paradigmas de masculinidade a fim de servirem ao Império Colonial Português.

PALAVRAS-CHAVE: Homem novo, colonialismo, masculinidade, nacionalismo.

\begin{abstract}
The concept of "new man" of the Estado Novo fomented much of Portuguese Colonial Literature, promoted by the contests of the General Agency of the Colonies (1926-1974). The narrative The spell of the Empire, in its dual form (film and novel), did not escape the rule, however, has proposed various forms of paradigms of masculinity in order to serve the Portuguese Colonial Empire.
\end{abstract}

KEYWORDS: New man, colonialism, masculinities, nationalism. 


\section{A AGC E OS CONCURSOS DE LITERATURA COLONIAL}

Nos estertores da Primeira República Portuguesa, o governo português, numa de suas iniciativas de política colonial, criou, em setembro de 1924, a Agência Geral das Colônias (AGC), com o intuito de fomentar a propaganda, captar recursos humanos e financeiros e, mais, estimular o interesse dos intelectuais portugueses pelo projeto colonial. Em janeiro de 1926, a AGC passou a publicar, sistematicamente, editais para o "Concurso de Literatura Colonial”, que, em 1954, foi substituído por quatro prêmios literários que subsistiram, até o derradeiro edital de 1974, com o título de "Concurso de Literatura do Ultramar", nos quais concorriam géneros literários diversos (conto, poesia, romance, teatro, além de reportagem jornalísticas e estudos de fundo acadêmico).

A criação da AGC se inseria num movimento geral das potências colonialistas que, com instituições semelhantes, se esforçavam por divulgar as riquezas e os valores "exóticos" das terras distantes em suas metrópoles europeias. Com dupla finalidade atrativa, investimentos e colonos, essas agências funcionavam como mediadoras entre os governos coloniais e seus potenciais parceiros. No caso português, a AGC foi uma "espécie de instituição 'nuclear' na produção e socialização da ideologia colonial ao longo dos diversos regimes portugueses do século XX" (GARCIA, 2011, p. 120).

A criação dos concursos de literatura colonial, além de divulgar o projeto colonial, pretendia preencher lacuna cultural e histórica, que alguns intelectuais identificados com o regime, como Carlos Selvagem ou José F. Ferreira Martins ou, mais tarde, Amândio Cesar, percebiam a respeito do colonialismo português - porque,

não se compreendia como um país que vivendo há séculos de aventuras marítimas e do contacto com outras civilizações ditas "exóticas", pudesse continuar a deter, exceptuando-se a literatura de viagens dos séculos XV e XVI, uma literatura tão pouco interessada com as personagens e os enquadramentos paisagísticos tropicais. $\mathrm{O}$ desinteresse por um manancial de valores humanos tão ricos e diferentes foi tal que nos poderia levar a supor que, dum povo com uma formação antropológica tão complexa e diversa, com uma geografia física especialmente virada para o mar e com uma história particularmente rica no enfrentar de novas situações, tivesse havido um comportamento literário tão pouco produtivo face à imensidade das fontes de inspiração. (GARCIA, 2011, p. 131)

O esforço da AGC estava evidentemente em consonância direta com um projeto imperial, característico do colonialismo europeu, que renascera nos fins do século XIX e que, por isso, buscava estabelecer uma continuidade imediata entre a metrópole e as colônias, como bem apontou Edward Saïd (SAID, 1995, p. 22). Os concursos de maneira direta investiam na criação de um imaginário capaz de fomentar não apenas uma identidade colonial e imperial, mas dar forma à identidade nacional por- 
tuguesa ressignificada pela consciência de pertencimento a um território pluricontinental.

Os intelectuais alinhados ao esforço colonial reconheciam que o panorama literário, no que dizia respeito aos espaços e aos episódios históricos coloniais, era bastante pobre, considerando a extensão do colonialismo na História portuguesa, especialmente se notassem a produção literária relativa às possessões coloniais desde a segunda metade do século XIX. A pouca produção, todavia, voltava-se flagrantemente ao território colonial angolano, como Augusto Casimiro, em África Nostra (1922), ou D. João Evangelista de Lima Vidal, em Por Terras de Angola (1916), ou, ainda, Hipólito Raposo, em Ana, a Kalunga (os filhos do mar) (1926) (cf. GARCIA, 2011, p. 509). Essas obras consistiam, entretanto, em narrativas colhidas esparsamente, relatos de viagens de militares ou de funcionários da administração colonial, carecendo muitas vezes de um explícito viés narrativo literário, objetivo necessário e reconhecido pela AGC. A primeira premiação do primeiro concurso (1926) foi dada à obra África portentosa, de Gastão de Sousa Dias, que consistia num conjunto de crônicas de viagens à Huila e ao Sul de Angola, sem haver, além dos recursos descritivos, a construção de uma narrativa literária.

Em África portentosa, como em várias obras premiadas nos anos seguintes, o espaço foi a categoria literária mais privilegiada, nas quais os aspectos humanos e culturais são obliterados em favor da exuberância natural, com nenhuma ou quase nenhuma recorrência a uma subjetividade diversa àquela que descreve o espaço. Apenas mais tarde, com as premiações sucessivas de Henrique Galvão $(1933,1934,1937)$ e de Castro Soromenho $(1939,1942,1943,1970)$, viria a emergir uma produção literária digna de nota, seja pela proposição e densidade narrativas, seja pela dupla articulação entre a observação e a análise do colonialismo, com a inserção, algumas vezes, de um posicionamento crítico, mesmo que velado (v. PADILHA, 2007; MARQUES, 2012). Nesse extenso conjunto de obras é flagrante a monotonia temática e estrutural, o que não encoraja a um estudo significativo de sua estética, bastante afastada de quaisquer tendências literárias do século XX (excetuando-se em obras cujas fortes tendências neorrealistas são flagrantes).

Os sessenta e oito títulos literários premiados, ao longo de quarenta e oito anos de concurso, não estiveram à parte do esforço geral que envolveu uma extensa rede de instituições, oficiais e não oficiais, que comungavam do mesmo ideal colonial e espírito imperial e que convergiam para a produção literária o seu esforço político de propaganda. Assim como o Secretariado de Propaganda Nacional (SPN), dirigido por António Ferro entre 1933 e 1949, orientava a política da propaganda do Estado, coube à AGC orientar a propaganda colonial, por isso, ao lado dos concursos literários, a agência criou a Divisão de Publicações e Biblioteca que, além do Boletim Geral das Colónias, passou a publicar obras diversas, sempre comprometidas com a difusão do projeto colonial. A coleção "Pelo Império", por exemplo, teve mais de cento e vinte títulos publicados entre 1934 
e 1947, e contava com obras de temas diversos, como biografias, notadamente de militares, clérigos e funcionários da administração colonial, ou narrativas, também de fundo histórico, de episódios considerados cruciais para o colonialismo, como a ênfase na ocupação do Brasil, de Angola ou Moçambique, e estudos mais específicos, de fundo etnográfico ou linguístico. Devendo figurar nas bibliotecas públicas e escolares, a coleção tinha firme propósito de fixar e propagar os paradigmas imperiais. Outro esforço de propaganda foi a edição de O Mundo Português - Revista de Cultura e Propaganda, Arte e Literatura Coloniais (1934-1947), periódico destinado a um público jovem, especialmente aquele inscrito na Mocidade Portuguesa. Em O mundo português, circulavam artigos de divulgação da cultura colonial, notas e relatos de viajantes, seções fotográficas e iconográficas com reproduções de "arte colonial", exemplos da literatura oral recolhida nas colônias, além de breves narrativas e poemas de autoria diversa (inclusive de brasileiros ${ }^{1}$ ), que, de alguma maneira, demonstrariam a "grandeza” do colonialismo em suas diversas formas. A revista, publicada em conjunto com o Secretariado de Propaganda Nacional (SPN), propunha-se a difundir o ideal colonial e o espírito imperial entre os jovens portugueses e lançava mão claramente do poder encantatório de narrativas de aventuras em terras exóticas, protagonizadas por heróis militares, sobretudo, e de exploradores e aventureiros portugueses, sem abrir mão de propagar a "responsabilidade" portuguesa com sua missão civilizadora e cristã.

O empreendimento colonial, no qual se envolviam a administração direta do Estado, as instituições militares e inúmeras empresas de exploração e comércio colonial, era acompanhado de perto por instituições da sociedade civil, especialmente editoras, mas também órgãos da imprensa civil, instituições escolares e universitárias, sociedades científicas e civis. Concomitantemente, outras editoras, como a Cosmos e a União Gráfica, de Lisboa, ou a Livraria Latina, no Porto, participavam desse esforço de propaganda e divulgação do projeto colonial. Juntando-se à AGC, publicaram obras premiadas ou destacadas pelos vários concursos literários chancelados pelo Estado e volumes diversos dedicados a biografias de heróis do colonialismo e a estudos de fundo histórico, etnográfico, econômico, administrativo ou linguístico. Enfim, uma bem elaborada rede urdida pelo Estado espraiava-se por vários meandros da sociedade portuguesa a fim de insuflar e construir a grandeza imperial, amparada no colonialismo.

Apesar de todo esse esforço, não se atraiu uma considerável massa populacional que se comprometesse com o colonialismo. ${ }^{2} \mathrm{O}$ imaginário que disso resultou, todavia, determinou hábitos e formas de compreensão do mundo, ao instituir uma equação imediata entre nacionalismo e colonialismo, para a qual a produção literária deu sentido e forma. ${ }^{3}$

\section{AS NARRATIVAS DA LITERATURA COLONIAL}

Nas narrativas da Literatura Colonial, o flagrante privilégio dado ao espaço obriga a observar a relação metonímica que essa categoria mantém com os personagens, tipos, em sua maior parte. Inúmeras des- 
sas narrativas lançaram mão desse artifício. Por exemplo, o romance de Reis Ventura, Queimados de sol (1966), seguiu a proposição da narrativa cinematográfica de Afonso Lopes Ribeiro, O feitiço do império (1940). O romance de Reis Ventura narra a irresistível atração do homem português pelo espaço africano, notadamente angolano, convertido no amor e na paixão pela mulher mestiça - numa quase releitura, arriscamos, de Nga Muturi, de Alfredo Troni (1882).

Em contraponto irresistível, observa-se a primeira obra de José Luandino Vieira, A cidade e a infância (2006, [1957]), especialmente o conto "A fronteira de asfalto". Narrativa considerada ainda bastante esquemática, como a estrutura do romance colonial, em "A fronteira de asfalto" é possível observar estratégias que, no universo colonial, impunham, a partir da ordem concedida pelo espaço, uma continuidade entre as relações étnico-raciais e as relações de gênero. A narrativa de Reis Ventura, no entanto, ao exaltar a comunhão racial, atendendo aos requisitos luso-tropicalistas da ideologia do estado da década de 1960, se contrapõe diretamente à fronteira de asfalto simbólica que se impunha na narrativa de Luandino Vieira. As relações de gênero, nesse conjunto, são determinadas pela estrutura colonial, entretanto, de maneira especular, ou seja, ao inverso. Ponto pacífico e bastante evidente, em se considerando a exaltação do ideal colonial e imperial presente naquela literatura. A literatura nacional angolana, através de Luandino Vieira, percebe e demarca exatamente a aporia do processo colonial, sem que seja possível a síntese pretendida pelo estado colonial na altura da premiação do romance de Ventura, já dado pelo confronto bélico com as forças de libertação nacional (desde 1961). Ao mesmo tempo, a atenção ao espaço, sempre bem caracterizado e efetivamente participante da narrativa de Vieira, é, na obra de Mota Junior, tratado de maneira enciclopédica, como uma recitação contínua de topônimos colhidos num atlas colonial - diferindo diametralmente da caracterização de espaço levada a efeito por Castro Soromenho, em Terra morta (1949) ou A chaga (1970).

É nessa perspectiva que se deve ter em conta a emergência de um conceito norteador da política interna do Estado Novo: o "homem novo". Extraído por Fernando Rosas do discurso de António de Oliveira Salazar, proferido na cidade de Braga por ocasião do décimo aniversário do golpe militar de 1926, o "homem novo" português seria moldado e capacitado pelo Estado, a fim de cumprir e interpretar a alma e o destino ontológico da nação que o antecedia e se lhe sobrepunha (cf. ROSAS, 2001, p. 10351036). Resultado de um amálgama de conceitos oriundos do comunismo soviético, do fascismo e do nazismo, o "homem novo" português opunha-se, sobretudo, ao modelo do homem moderno, comprometido com a cultura burguesa cosmopolita, urbana e hedonista, que florescera na segunda metade do século XIX, identificando-se com uma tradição rural e católica. Submetia-se não apenas às razões do estado, mas também à crença inquestionável nessas razões, inserido num "hábito" cujo fim seria a estabilidade do estado e, por conseguinte, da sociedade. Comprometendo-se com a manutenção e a propagação da "civilização portuguesa" (onde se incluía a 
pobreza e o culto ao passado e dos heróis nacionais), o "homem novo" estadonovista seria, enfim, o mais bem acabado produto da "mística imperial", agente da missão civilizadora do Império.

Ao lado do ideal do "homem novo" estadonovista, vicejou, em oposição, o modelo do "marialva", assinalado por Miguel Vale de Almeida (1997), seguindo a proposição do escritor José Cardoso Pires (1960). Ambos presentificam-se nas páginas da Literatura Colonial, em contraponto evidente. Se o primeiro foi o colonizador embevecido pelas colônias, cheio de boas intenções e ideais desenvolvimentistas, poucas vezes, ou nunca problematizador, crítico ou efetivamente modificado pelas culturas locais, o segundo foi o português alienado dos ideais do Estado, desinteressado pelo projeto nacional, de origem aristocrata ou burguesa, e, essencialmente, individualista. No entanto, ambos serão "enfeitiçados” pelo Império. Como se verá mais adiante, especificamente na dupla forma narrativa de $O$ feitiço do império, a caracterização do "homem novo" do Estado Novo, nas obras da literatura colonial, foi um objetivo permanente daquela produção, especialmente após as problemáticas premiações sucessivas de Henrique Galvão.

\section{O FEITIÇO DO IMPÉRIO}

O romance $O$ feitiço do Império, de Joaquim Mota Junior, foi publicado em 1940 pela Agência Geral das Colônias, ao mesmo tempo em que era lançada a produção cinematográfica homônima de António Lopes Ribeiro, ambos no bojo das comemorações do duplo centenário da fundação e da restauração portuguesa e da Exposição do Mundo Português.

Luís Reis Torgal (2000) já analisou com bastante propriedade a forma como ambas as produções se assemelham e diferem entre si; mas, mais do que o percurso literário e cinematográfico das narrativas, importa, aqui, partir da reflexão de Patrícia Vieira (2001), que atenta para o fetiche do Império que o filme, e o romance, acrescentamos, evocavam. Além disso, deve-se perceber que não se pode desviar os olhos dos processos de "reconhecimento", muitas vezes travestido de "iluminação", sofridos pelas personagens na medida em que o espaço colonial deixa de ser uma mera expressão da beleza e exuberância naturais para se converter em palco e cenário de tensões narrativas do qual emerge o "homem novo", projetado pelo Estado Novo.

Tanto Torgal, quanto Vieira chamam a atenção para o forte objetivo de propaganda colonial e nacionalista contido em ambas narrativas. No entanto, pouco atentaram, apesar de sublinharem vivamente as peripécias do protagonista (Luis Moraes, no filme; Eduardo Carraca, no romance) em direção à sua conversão aos ideais do Estado Novo, para os aspectos que o submetem ao paradigma do "homem novo" do Estado Novo.

O storyboard do romance e do filme, basicamente, é o mesmo. Um filho de emigrantes portugueses nos Estados Unidos da América faz uma viagem a Portugal e às colônias antes de casar-se com uma mulher norte-americana. O protagonista, em ambas as produções, encontra-se em 
estado de dormência/alienação, provocado pelo conforto que a sociedade industrial e moderna dos EUA proporcionaria; a viagem às colônias portuguesas despertar-lhe-á uma consciência da "portugalidade", o "reconhecimento" do qual desperta da condição alienada. A partir daí começam as divergências.

No filme, a noiva americana, Fay Gordon, é caracterizada de maneira fútil e frívola, enquanto que, no romance, Gail Dorland, é uma mulher dotada de inteligência, coragem, disciplina e sensibilidade. Da relação com esta mulher, o protagonista irá atingir a consciência e o "reconhecimento" necessários para a emergência do "homem novo". A frivolidade de Fay permite a Eduardo reconhecer em Mariazinha, a filha de portugueses radicados em Angola, o instrumento de conversão necessária; por sua vez, no romance, será Gail quem oferecerá a Eduardo a consciência e os meios para o "reconhecimento". A narrativa de Mota Junior se apresenta, dessa maneira, muito mais complexa do que a de Lopes Ribeiro. A consciência da portugalidade e a consequente transformação do protagonista no paradigma do "homem novo" emergem não pela negação dos valores cosmopolitas representados por sua raiz norte-americana, mas pela síntese do mundo português, "do Minho ao Timor", como bem lembra Torgal, que se converte numa nação espiritual e que se representa e se apresenta onde quer que a cultura portuguesa se instale.

Torgal chama, ainda, a atenção para o fato de o cinema oficial português ter sido fomentado por técnicos alemães na altura do nazismo e que, por isso, a proposta de síntese de Mota Junior ter sido inaceitável para os padrões cinematográficos do Estado Novo, na medida em que há uma evidente simpatia para com os Estados Unidos, efetivamente representado por Gail.

De Mota Junior resultaria um "homem novo" mais afeito ao espírito universalista de tendências liberais, apesar de claramente vinculado ao exercício colonial. O marialvismo característico da vida norte-americana seria ainda produtivo para a síntese pretendida, na medida em que a união com a mulher norte-americana apontaria para o viés cosmopolita da cultura portuguesa. A narrativa da variante cinematográfica resultaria numa proposição bem mais próxima da pedagogia estadonovista. No entanto, o "homem novo" resultante, em ambas as narrativas, não perde a força paradigmática. Luis/Eduardo convertido é o agente necessário para a disseminação do Império, mesmo que com sentidos diversos. Nota-se, entretanto, que o conceito de Império que decorre da narrativa literária é mais amplo do que aquele que o filme apresenta.

A nação portuguesa espiritualizada por Mota Junior se assenta sobre um ideal de solidariedade e colaboração entre os diversos povos com os quais os portugueses teriam tido contato ao longo da sua história, aproximando-se, deveras, antecipadamente, da ideologia oficial que capturou o luso-tropicalismo; ao passo que a narrativa de Lopes Ribeiro redunda diretamente nos aspectos mais visíveis do colonialismo, já que exalta a superioridade da identidade nacional ao submeter Luís a um processo efetivo 
de "conversão" ao estadonovismo, como é destacado por Patrícia Vieira, ao comentar a sequência narrativa da recuperação do protagonista após a caçada a um leão:

Apesar da aparente vitória de Luís sobre a natureza africana, simbolizada pela morte do leão, o protagonista sai transformado deste encontro. [É colocada] [...], na cabeceira da qual se encontra [em recuperação] uma imagem da Virgem Maria com Jesus. Ao acordar, Luís está fora de perigo e a câmera move-se em travelling que vai do protagonista à estátua da Virgem, sugerindo que se deve a ela a cura do luso-americano (VIEIRA, 2011, p. 153)

A sequência parece submeter imediatamente o protagonista de Lopes Ribeiro ao paradigma da religiosidade estatal, representada no Decálogo do Estado Novo (1934), ao mesmo tempo em que o submete às razões do Estado, amalgamado à nação, e metonimizado por Mariazinha. É dessa sequência em diante que o protagonista, já "convertido", abandonará o projeto de casamento com Fay e decidirá pela união com Mariazinha. Assim como acontecera com Gonçalo Mendes Ramires, protagonista d'A ilustre casa de Ramires, de Eça de Queirós (1901), Luís Moraes é renovado pela África e pelo Império, na medida em que esse "homem novo" só emerge nas fronteiras mais distantes desse espaço de dominação e onde pode exercer a sua forma mais evidente de masculinidade hegemônica pela força, pelo trabalho, pela religião, pela honra, pela ordem, pelo Estado.

Em contrapartida, o "reconhecimento" de Eduardo, no romance de Mota Junior, e a consequente emergência do "homem novo" se dão pelo contato com a diversidade cultural e pela consciência da extensão espiritual do Império para além das fronteiras coloniais. Torgal assinala que:

However, the "sovereignty" of "blood" has its "limits" and the human being can be formed by education: in Eduardo's case, it is the disciplined education of the American. However, the Portuguese case is obviously the most relevant and, therefore, the most analyzed in the conversation between Gail and Eduardo. These reflections make us think in the sense, or in the senses, of the "Portuguese Empire". (TORGAL, 2013).

O sentido desse Império, na narrativa de Mota Junior, parece estar na relação estabelecida entre Eduardo e Gail, através da união que irá se consumar ao fim do romance, no Mosteiro dos Jerônimos. Contudo, a relação depende da conversão de Eduardo, provocada por Gail, ao mesmo tempo em que a submete à "ternura" portuguesa, virtude exaltada pelo romance, frente à disciplina norte-americana. O "homem novo" de Mota Junior, mais do que submetido às razões de Estado, submete-se à "portugalidade”, pondo a nação acima do Estado. A sutileza parece ferir o já citado Decálogo do Estado Novo (1934) e, portanto, colocando em risco as assertivas e os paradigmas oficiais. 


\section{PROSPECÇÃO}

O modelo de "homem novo" do Estado Novo, nas narrativas da Literatura Colonial, perdurou pelo menos até os estertores do 25 de Abril de 1974. O já referido romance de Reis Ventura, Queimados de sol (1966), investiu no modelo, mesmo que agora a África/Angola, fosse metonimizada por uma mulher mestiça. No entanto, prevalecia o paradigma simplório de Afonso Lopes Ribeiro - monoliticamente petrificado pelo Estado ao insistir na condição colonial.

O conceito de "homem novo" foi suficientemente forte, todavia, para fecundar a literatura de resistência ao colonialismo e as literaturas nacionais dos povos africanos. Como não recorrer ao poema "Consciencialização", de Agostinho Neto, ou o conto "A menina Vitória”, de Arnaldo Santos, e pensar que o reconhecimento experimentado pelo sujeito poético de Neto ou pelo protagonista de Santos não fosse também a emergência de um sujeito da nacionalidade africana, identificado por ideais de masculinidades revistas.

A correlação, entretanto, entre imperialismo, colonialismo, nacionalismo e masculinidades ainda precisa ser exaustivamente explorada a fim de não se repetirem os paradigmas críticos que, em nome de uma suposta tradição, obliteram a extensão do colonialismo para além da dominação efetiva de territórios.

A observação da Literatura Colonial portuguesa, compreendida para além de seu excessivo comprometimento ideológico e sua "pobreza" literária, abre caminhos para a construção de um quadro cultural detalhado do colonialismo português, especialmente no que tange à atenção da crítica literária, voltada especialmente para o neorrealismo ou para as narrativas fundadoras das literaturas nacionais africanas.

\section{REFERÊNCIAS BIBLIOGRÁFICAS}

ALMEIDA, Miguel Vale de. Marialvismo. Fado, touros e saudade como discursos da masculinidade, da hierarquia social e da identidade nacional. Trabalhos de Antropologia e Etnologia, v. 37 (1-2) 1997: 41-66.

FERRO, António. Decálogo do Estado Novo. Lisboa, SPN, 1934. p. 8-10.

GARCIA; José Luís Lima. Ideologia e propaganda colonial no Estado Novo: da Agência Geral das Colónias à Agência Geral do Ultramar (19241974). 2011. Tese (Doutorado em História). Coimbra: Universidade de Coimbra, 2011.

GOMES, Miguel (dir.). Tabu. Portugal, Brasil, Moçambique, Alemanha: O Som e a Fúria/ Komplizen Film/ Gullane Filmes/ Shellac Sud, 2012.

MOTA JUNIOR, Joaquim. O feitiço do império. Lisboa: Agência Geral das Colónias, 1940. 
PADILHA, Laura C. Entre voz e letra: o lugar da ancestralidade na ficção angolana do século XX. $2^{a}$ ed. Niterói / Rio de Janeiro: EdUFF / Pallas, 2007.

MARQUES, Diego Ferreira. O carvalho e a mulemba. Angola na narrativa colonial portuguesa. Tese (Doutorado em Antropologia). Campinas, Universidade de Campinas, 2012.

RIBEIRO, António Lopes (dir.). O feitiço do Império. Portugal: Secretariado de Propaganda Nacional/ Agência Geral da Colónias, 1940.

ROSAS, Fernando. O salazarismo e o homem novo ensaio sobre o Estado Novo e a questão do totalitarismo. Análise Social, vol. XXXV, (157), 2001, 1031-1054.

SAID, Edward W. Cultura e imperialismo. São Paulo: Companhia das Letras, 1995.

TORGAL, Luis Reis. "Propaganda, ideology and cinema in the Estado Novo of Salazar: The conversion of the unbelievers". In: Contemporary Portuguese History on line. http://www.cphrc.org/index.php/essays/ eswopa/156-propaganda-ideology-and-cinema-in-the-estado-novo-of-salazar-the-conversion-of-the-unbelievers . Acesso em 17/01/2013.

VENTURA, Reis. Queimados de sol [Metrópole e Ultramar, 6]. Braga: Pax, 1966.

VIEIRA, Luandino. A cidade e a infância. São Paulo: Companhia das Letras, 2006.

VIEIRA, Patrícia, Cinema no Estado Novo: a encenação do regime. Lisboa: Colibri, 2001.

Recebido para publicação em 27/11/14

Aprovado em 18/01/15

\section{NOTAS}

1 No seio da retórica imperial/colonial do Estado Novo, lugar especial foi dado ao Brasil, "a mais bem acabada obra do colonialismo português", segundo os vários discursos que se ampararam antes e depois da propagação do pensamento de Gilberto Freyre, tanto em Casa grande \& Senzala (1933), quanto em Sobrados e Mocambos (1936). Narrativas sobre os missionários católicos e a ocupação do território brasileiro, de campanhas militares e biografias de vultos de nossa história colonial, serviam de espelho para a formulação de um imaginário colonial que, atualizado, era o "destino" e parte inseparável da identidade do povo português.

2 Deve-se assinalar o movimento contraditório à política do Estado das inúmeras vagas migratórias de portugueses para o Brasil, EUA e norte da Europa, ao longo dos anos de duração do Estado Novo.

3 A recente produção cinematográfica Tabu (2012), dirigida por Miguel Gomes, evidencia bem não apenas a equação entre nacionalismo e colonialismo, mas a forma como o colonialismo constituiu um imaginário capaz de subsistir por décadas depois de sua derrocada. 